\title{
Ring Chromosome 18: Clinical, Cytogenetic and Molecular Genetic Studies on Four Patients
}

\author{
Matild Dobos ${ }^{1}$, György Fekete ${ }^{1}$, Ruth Raff², Regine Schubert² ${ }^{2}$ Judit Szabó ${ }^{1}$, Zita Halász ${ }^{1}$, Valeria \\ Lukács $^{3}$, Thomas Eggermann ${ }^{4}$ and Gesa Schwanitz ${ }^{2}$ \\ 1. Semmelweis University, II. Department of Pediatrics, Budapest, Hungary \\ 2. Institute of Human Genetics, University of Bonn, Germany \\ 3. Borsod Country Hospital, Miskolc, Hungary \\ 4. Institute of Human Genetics, Technical University of Aachen, Germany
}

KEYWORDS Parental origin of ring chromosome 18; microsatellite typing; ring chromosome formation

\begin{abstract}
Ring chromosomes are a rare chromosomal aberration but have meanwhile been reported for nearly all human chromosomes. We describe four de novo carriers (1 boy and 3 girls) of ring chromosome 18 (r(18)): while three patients had a non-mosaic 46,r(18) karyotype, the fourth was a mosaic: mos 46,XX,r(18)/46,XX,der(18). Phenotypically, the boy showed only minor anomalies, but the female probands presented several clinical features, among them microcephaly, a moderate to severe muscular hypotonia, psychomotoric retardation and short stature. Major malformations were heart defects, cleft lip and palate and atresia of the external auditory canal. In one girl with very short stature, we found a hypothalamic growth hormone deficiency. By investigating the children over 2,5 years it could be demonstrated that the ring chromosomes were passed regularly through mitosis. The parental origin of the ring was determined in three cases indicating a postzygotic mitotic error.
\end{abstract}

\section{INTRODUCTION}

Ring chromosomes are uncommon cytogenetic findings, they nearly always arise denovo (Schinzel et al. 2001). The classic mode of ring formation is breakage in both arms of the affected chromosome, with fusion of the breakpoints and loss of the distal fragments. This rearrangement therefore results in partial monosomies for the distal short and long arms. The severity of clinical features of ring chromosome carriers depends on the extent of the deleted chromosomal segments.

Rings of chromosome $18(\mathrm{r}(18))$ are frequent among ring chromosomes; dependent on the size of the deleted regions in 18p and 18q, the clinical symptoms of r(18) correspond more or less to the typical signs of the $18 \mathrm{p}$ and $18 \mathrm{q}$ deletion syndromes (de Grouchy 1969; Grosse et al. 1972; Schinzel 2001). Thus, the $\mathrm{r}(18)$ phenotype is characterised by developmental retardation, moderate to severe mental retardation and mainly unspecific anomalies. Facial dysmorphisms and malformations can be present (Table 1).

Here we present cytogenetic and molecular genetic data on four new cases of ring chromosome 18. Clinical signs in our patients are compared with cases from the literature and illustrate the broad phenotypic spectrum.

\section{MATERIALS ANDMETHODS}

Metaphases were prepared after $72 \mathrm{~h}$ lymphocyte cultures, chromosomes were analysed by GTG banding. FISH was carried out using commercially available probes (wcp18 and DXZ1, Oncor) according to the manufacturer 's instructions. The DNA of patients and their parents was extracted from peripheral blood lymphocytes by a simple salting-out procedure. The parental origin of the ring chromosomes was determined by microsatellite typing in patients 2 , 3 and 4 (Table 2). Primers and PCR conditions can be asked from the authors. After denaturing sequencing gel electrophoresis, the alleles were visualised by silver-staining.

\section{CLINICAL REPORTS}

Patient 1: The boy was born at term after an uncomplicated pregnancy and delivery. Birth weight was $2900 \mathrm{~g}\left(25^{\text {th }} \mathrm{p}\right)$, length $51 \mathrm{~cm}\left(25^{\text {th }} \mathrm{p}\right)$, and head circumference (OFC) $36 \mathrm{~cm}\left(50^{\text {th }} \mathrm{p}\right)$. Maternal and paternal ages were 35 and 43 years, respectively; the three half-sibs are healthy. At 9 weeks of life, the boy presented brachycephaly $(\mathrm{OFC} 40 \mathrm{~cm})$, a hypertelorism, epicanthal folds, a flat broad root of the nose, dysplastic ears, a short neck, short humerus and a reduced length 
Table 1: Frequency of anomalies associated with ring chromosome 18 according to *Dötsch et al. (1995) and the clinical features in the four patients presented here.

\begin{tabular}{|c|c|c|}
\hline Symptoms & $\begin{array}{l}\text { requency } \\
(\%) *\end{array}$ & $\begin{array}{c}\text { Frequency } \\
\text { in the } \\
\text { four patients } \\
\text { presented here }\end{array}$ \\
\hline Growth retardation & 85 & $3 / 4$ \\
\hline $\begin{array}{l}\text { Psychomotoric/mental } \\
\text { retardation }\end{array}$ & 91 & $3 / 4$ \\
\hline \multicolumn{3}{|l|}{ Craniofacial Dysmorphisms } \\
\hline Microcephaly & 86 & $3 / 4$ \\
\hline Hypertelorism & 76 & $4 / 4$ \\
\hline Epicanthus & 73 & $4 / 4$ \\
\hline Ptosis & 73 & $1 / 4$ \\
\hline Strabism & 58 & $1 / 4$ \\
\hline Bulbus anomalies & 63 & $1 / 4$ \\
\hline Pseudoentropium of lower lid & id 61 & $0 / 4$ \\
\hline Flat broad nose root & - & $3 / 4$ \\
\hline Midface dysplasia & 83 & $3 / 4$ \\
\hline Low set, dysplastic ears & 68 & $3 / 4$ \\
\hline $\begin{array}{l}\text { Cleft lip/palate, high } \\
\text { arched palate }\end{array}$ & 43 & $1 / 4$ \\
\hline $\begin{array}{l}\text { Downturned corners } \\
\text { of the mouth }\end{array}$ & 88 & $3 / 4$ \\
\hline Micrognathia & 40 & $2 / 4$ \\
\hline \multicolumn{3}{|l|}{ Neck, Thorax and Abdomen } \\
\hline Short neck & 71 & $1 / 4$ \\
\hline Webbing of the neck & 100 & $2 / 4$ \\
\hline Vertebral or rib anomalies & 70 & $1 / 4$ \\
\hline Widely separated nipples & 67 & $1 / 4$ \\
\hline \multicolumn{3}{|l|}{ Limbs } \\
\hline Microacrodactyly & 80 & $3 / 4$ \\
\hline \multicolumn{3}{|l|}{ Genitalia } \\
\hline $\begin{array}{l}\text { Abnormalities of } \\
\text { extranl genitalia }\end{array}$ & 15 & $0 / 4$ \\
\hline \multicolumn{3}{|l|}{ Other Malformations } \\
\hline External auditory canal atresia & a 61 & $1 / 4$ \\
\hline Heart defects & 53 & $3 / 4$ \\
\hline Kidney anomalies & 15 & $0 / 4$ \\
\hline $\begin{array}{l}\text { brain anomalies/ } \\
\text { holoprosencephalus }\end{array}$ & 10 & $0 / 4$ \\
\hline Impaired hearing & 71 & $1 / 4$ \\
\hline Reduction of serum IgA & 39 & $0 / 3$ \\
\hline Hypotonia & 85 & $3 / 4$ \\
\hline
\end{tabular}

of phalangs. His somatic development was normal (weight $5920 \mathrm{~g}=50^{\text {th }} \mathrm{p}$ ). At the age of 5 months psychomotoric development and hearing were normal. He has no major malformations. Subsequent investigation was not possible.

The $\mathrm{r}(18)$ chromosome was present in 100 diploid cells. Parental karyotypes were normal. Patient 2: The girl was born at the $39^{\text {th }}$ week of gestation after an uneventful pregnancy. She was the second child of healthy and unrelated parents (27 and 28 years). The patient has three healthy siblings. Birth weight was $3050 \mathrm{~g}\left(25^{\text {th }} \mathrm{p}\right)$, length $47 \mathrm{~cm}\left(<3^{\text {rd }} \mathrm{p}\right)$, and OFC $32 \mathrm{~cm}\left(<3^{\text {rd }} \mathrm{p}\right)$. External clinical findings at the age of 3 weeks were brachycephaly, microcephaly, microphthalmos, ptosis of eyelid on the right side, a hypertelorism, epicanthal folds, a broad nasal bridge, a high arched palate, micrognathia, low-set dysplastic ears, a short neck, reduced length of phalangs, syndactyly II/III (cutaneous) of the feet and a severe hypotonia. Furthermore, she presented an atrial septal defect (ASD II). At the age of 10 months developmental delay (somatic and motoric) was evident with severe muscular hypotonia. Clinical investigations at the age of 18 months revealed her weight to be $7400 \mathrm{~g}$, length $76 \mathrm{~cm}$ and OFC $42 \mathrm{~cm}$ (all below the $3^{\text {rd }} \mathrm{p}$ ). She was able to walk with help, hearing was normal, but she did not speak. Cardiac problems were not reported. She started to walk at the age of 24 months, her development was approximately at the 12-months level. Due to the very short stature responses to growth hormone provocating tests were analysed (insulin and DOPA). Although the base blood growth hormone level was normal, the mean value of blood growth hormone levels obtained at $15 \mathrm{~min}$ intervals for $60 \mathrm{~min}$ and at the $90 \mathrm{~min}$ were low, indicating the existence of growth hormone neurosecretory dysfunction. The girl was euthyreotic, the secretion-capacity of ACTH and cortisol was normal.

The $r(18)$ was present in all 39 investigated mitoses. The karyotypes of the parents and the siblings were normal. The second cytogenetic analysis at the age of 18 months showed the $\mathrm{r}(18)$ in all 100 investigated mitoses. Typing of microsatellite markers in distal $18 \mathrm{p}$ and $18 \mathrm{q}$ revealed the paternal origin of the marker (Table 2).

Patient 3: The girl was born as first child after an uneventful pregnancy, delivery was uncomplicated. The parents are healthy (19 and 25 years). One cousin of the proband has a cleft lip. The birth weight was $2900 \mathrm{~g}$, length $51 \mathrm{~cm}$ (both $25^{\text {th }}$ p), the OFC $31 \mathrm{~cm}\left(<3^{\text {rd }} \mathrm{p}\right)$. The patient was referred to our pediatric centre at the age of 2 months because of multiple malformations: she showed a microcephaly, cleft lip and palate, stenosis of the arteries pulmonary, umbilical hernia and hypotonia. At the age of 14 months she was developmentally delayed. The cleft lip and palate were operated, the umbilical hernia closed. She was able to sit but not to stand. At the age of 32 months her length was $86 \mathrm{~cm}$, weight $10,4 \mathrm{~kg}$, OFC $45 \mathrm{~cm}$ (all values $<3^{\text {rd }} \mathrm{p}$ ). Clinical 
Table 2: Results of microsatellite typing in three of our four $r(18)$ patients.

\begin{tabular}{|c|c|c|c|c|c|c|c|c|c|}
\hline \multirow[t]{2}{*}{ STR } & \multicolumn{3}{|c|}{ Case 2} & \multicolumn{3}{|c|}{ Case 3} & \multicolumn{3}{|c|}{ Case 4} \\
\hline & Father & Mother & Patient & Father & Mother & Patient & Father & Mother & Patient \\
\hline \multicolumn{10}{|l|}{18 pter } \\
\hline D18S59 & $1-1$ & $1-2$ & 2 & $2-2$ & $1-1$ & $1-2$ & $2-2$ & $1-1$ & 1 \\
\hline D18S54 & - & - & - & $1-2$ & $2-2$ & $2-2$ & $2-2$ & $2-2$ & $1-2$ \\
\hline \multicolumn{10}{|l|}{ Cen } \\
\hline PACAP & - & - & - & - & - & - & $1-1$ & $2-2$ & $1-2$ \\
\hline D18S46 & $1-3$ & $2-3$ & $2-3$ & $1-2$ & $2-3$ & $2-3$ & - & - & - \\
\hline D18S497 & $1-2$ & $2-2$ & 2 & $2-4$ & $1-3$ & 4 & $2-4$ & $1-3$ & 3 \\
\hline D18S61 & $1-1$ & $1-2$ & 2 & 2 & - & $1-2$ & $1-2$ & $2-3$ & 2 \\
\hline D18S70 & $1-2$ & $1-3$ & 3 & $2-2$ & $1-1$ & 2 & $2-4$ & $1-3$ & 3 \\
\hline $18 \mathrm{qter}$ & & & & & & & & & \\
\hline
\end{tabular}

findings included strabism and astigmatism. MRI of the brain and hearing were normal.

The karyotype of the proband was 46,XX,r(18); parental karyotypes were normal. The cytogenetic analysis was repeated at the age of 32 months, in all 50 mitoses the r(18) was present.

Molecular genetic investigations showed the $\mathrm{r}(18)$ to be of maternal origin (Table 2).

Patient 4: The girl was born at term as the second child of healthy and unrelated parents (23 and 27 years). She has one healthy sister. Pregnancy and delivery were uneventful. Birth weight was $2700 \mathrm{~g}\left(25^{\text {th }} \mathrm{p}\right)$, length $49 \mathrm{~cm}\left(10^{\text {th }} \mathrm{p}\right)$, head circumference $34 \mathrm{~cm}\left(25^{\text {th }} \mathrm{p}\right)$. On examination at the age of 4 months the patient was markedly retarded, her weight was under her birth weight. Clinical findings included hypertelorism, epicanthal folds, carp-shaped mouth, a broad nasal bridge, low set ears, atretic ear canals on both sides, high arched palate, spindle fingers. Moderate muscular hypotonia and ventricular septal defect could be diagnosed.

Karyotype after lymphocyte culture at the age of 4 months revealed a mosaic karyotype mos46,XX,r(18)[56]/46,XX,der(18)[11],GTG. While the paternal karyotype was normal, the mother showed a triple-X-mosaic $(\operatorname{mos} 47, \mathrm{XXX}$ [15]/46,XX[85] ). At the age of 28 months the patient and her mother were reinvestigated. A total of 100 mitoses were analysed in each case: in the patient, the r(18) was detected in $12 \%$ of the mitoses, and the derivate chromosome 18 in $88 \%$ of the mitoses. The marker proved to be a derivate of chromosome 18. The FISH analysis showed that the deleted region was not translocated to another chromosome.

FISH analysis using a $\mathrm{X}$ specific probe (DXZ1) confirmed a triple X-mosaicism in the mother: now $7 \%$ of the mitoses were trisomic (karyotype: mos 47,XXX.ishX(DXZ1+++)[7]/ 46,XX.ishX(DXZ1++)[93]). The phenotype of the mother was normal.

DNA analysis showed that the paternal chromosome 18 was involved in the $\mathrm{r}(18)$ formation (Table 2).

\section{DISCUSSION}

The $r(18)$ syndrome is characterised by severe mental and growth deficiency, microcephaly, brain and ocular malformations, hypotonia, microacrodactyly and other skeletal abnormalities in different frequencies (Table 1). Facial dysmorphisms include midface dysplasia, epicanthal folds, hypertelorism, down-turned corners of the mouth, micrognathia, low-set and dysplastic ears and webbing of the neck. The majority of patients show a clinical picture reminding to the 18q- syndrome (MaaswinkelMooij et al. 1993; Schinzel 2001). Because of the terminal deletion of the $p$ arm the clinical symptoms of $18 \mathrm{p}$ - syndrome can also be observed (De Grouchy 1969; Kunze et al. 1972; Grosse et al.1972; Kunze et al. 1976).

The clinical features of our four patients are compatible with the aforementioned r(18) characteristics (Table 1), their frequencies in our patients correspond to the frequencies reported by Dötsch et al. (1995). Growth retardation, hypotonia and psychomotoric/mental retardation as the major symptoms were present; craniofacial key features consist of microcephaly, epicanthus, downturned corners of the mouth and micrognathia. Furthermore, webbing of the neck, microacrodacytyly and heart defects were detected more than once in our patients. However, the comparison of our cases with the 
data from the literature impressively illustrates the broad phenotypic spectrum of $\mathrm{r}$ (18) syndrome.

Our three female patients reveal a significant growth retardation. It has been postulated that all carriers of a ring autosome show a phenotype with short stature as a consistent criterion for "ring syndrome", regardless of which autosome is involved (Kosztolányi 1987, 1991). More data raise the possibility of the growth hormone deficiency in patients with del(18p) and in patients with $\mathrm{r}(18)$ (Abusrewill et al. 1988; Artmann et al. 1992; Meloni et al. 1994; Aritaki et al. 1996). In one of our patients the absent responses to insulin-hypoglycaemia stimulated GH secretion refer to the hypothalamic origin of the defect. Meloni et al. (1994) supposed that this finding may be explained by the presence of gene(s) crucial for normal hypothalamic development and function on the short arm of chromosome 18.

In three of our cases, the parental origin of the ring was determined: in two the paternal chromosomes 18 were affected, in one the maternal chromosome 18 (Table 2). Although this is only a small number of cases and the cell stage of ring formation can not be determined due to the nature of this aberration, these findings allow interesting insights in $\mathrm{r}(18)$ formation: in other aberrations of chromosome 18 , i.e. trisomy 18 and isochromosome $18 \mathrm{p}$ there is a strong preponderance of cases originating from a maternal meiosis error (Fisher et al. 1995; Eggermann et al. 1999). Since we determined two cases with paternal $\mathrm{r}(18)$ and meiotic nondisjunction of the paternal chromosome 18 has rarely been described, it can be speculated that rings of chromosomes 18 mainly derive from a postzygotic mitotic error. This observation is an agreement with the de-novo formation of the majority of ring chromosomes.

There was no difference in the severity of the phenotypes between our patients with paternally and with maternally derived deletions.

In general, children with ring chromosome 18 usually show an unspecific pattern of clinical symptoms. Therefore, they are often diagnosed for the first time at an age of two years and older. As the frequent atresia of the external ear channel requires an early treatment to correct the hearing impairment consideration of facial and other dysmorphisms to initiate a chromosomal analysis as early as possible is of great therapeutic and prognostic importance.

\section{ACKNOWLEDGEMENT}

This study was supported by the DAAD.

\section{REFERENCES}

Abusrewill S, McDermott A, Savage DCL 1988. Growth hormone, suspected gonadotropin deficiency, and ring 18 chromosome. Arch Dis Child, 63: 10901091.

Aritaki S, Tagaki A, Someya H, Jun L 1996. Growth hormone neurosecretory dysfunction associated with ring chromosome 18. Acta Paediatr JPN, 38:544-548.

Artman HG, Morris CA, Dean Stock A 1992. 18psyndrome and hypopituitarism. Med Genet, 29: 671672.

Dötsch J, Förster, W, Kuhl PG 1995. Ringchromosom 18 bei einem Neugeborenen. Monatsschr Kinderheilk, 143: 489-492.

Eggermann, Schubert R, Engels H, Apacik C, StengelRutkowski S, Haefliger C, Emiliani V, Ricagni C, Schwanitz G 1999. Formation of supernumerary euchromatic short arm isochromosomes: parent and cell stage of origin in new cases and review of the literature. Ann Génét, 42: 75-80.

Fisher JM, Harvey JF, Morton NE, Jacobs PA 1995. Trisomy 18: studies of parent and cell division of origin and the effect of aberrant recombination on nondisjunction. Am J Hum Genet, 56: 669-675.

Grosse KP, Schwanitz G, Rott HD, Klein K, von Zyl J 1972. The E-18 ring chromosome- case report and survey. Klin Pädiatr, 184: 495-500.

DeGrouchy J 1969 . The $18 \mathrm{p}-$, $18 \mathrm{q}-$ and $18 \mathrm{r}$ syndromes. Birth Defects, V: 74-79.

Kosztolanyi G 1987. Does "ring syndrome" exist ? An analysis of 207 case reports on patients with ring autosome. Hum Genet, 75: 174-179.

Kosztolanyi G, Méhes K, Hook EB 1991. Inherited ring chromosomes: an analysis of published cases. Hum Genet, 87: 320-324.

Kunze J, Stephan M, Tolksdorf M 1972. Ringchromosom 18 - 18p/18q- Syndrom. Humangenetik, 15: 289318.

Kunze J, Spranger J, Tolksdorf M 1976. Ring-Chromosom 18. Monatsschr Kinderhlkd, 124: 41-42.

Masswinkel-Mooij PD, de Jong P, Beverstock GC 1993. 46,XYdel(18)(q21.3q22.2) with mosaicism of $r(18)$ and a milder form of the 18q- syndrome. Clin Genet, 43: $76-78$.

Meloni A, Boccone L, Angius L, Loche S, Falchi AM, Cao A 1994. Hypothalamic growth hormone deficiency in a patient with ring chromosome 18 . Eur J Pediatr, 153: 110-112.

Schinzel A 2001. Catalogue of Unbalanced Chromosome Aberrations in Man. $2^{\text {nd }}$ Ed., Berlin: deGruyter, pp. 604-618. 